\title{
Organic Chemistry Frontiers
}

\section{ARTICLE}

\section{Towards taxanes analogues synthesis by dienyne ring closing metathesist}

Received 00th January 20xx, Accepted 00th January 20xx

DOI: $10.1039 / x 0 x \times 00000 x$

www.rsc.org/

\section{S. Pérez-Estrada, N. Sayar and J. R. Granja*}

Herein we report the facile construction of taxadiene analogues by ring closing metathesis of dienynes built on a cyclohexanenone with nantural configuration at $\mathrm{C} 1$ and its further transformation to incorporate most of the key funtional groups of taxol.

\section{Introduction}

Taxol (1, Scheme 1$)$ is a natural product widely prescribed for the treatment of various types of cancer, for example, ovarian, breast, lung and liver. ${ }^{1}$ The high demand of this drug has stimulated intensive research that aims to find easy-to-access and thus inexpensive sources of supply. ${ }^{2}$ Despite the health improvement of patients with cancer, harmful side effects, drug resistance development, and poor water solubility ${ }^{3}$ are problems that call for further research to find less structurally complex and easy to prepare analogues that show improved physical and anticancer properties. On the other hand, from the perspective of synthetic chemists, the taxol structure represents a significant challenge because of the large number of stereogenic centres, as well as its highly congested and densely oxygenated tetracyclic structure. ${ }^{1 \mathrm{e}}$ To date, multiple approaches have been taken to the synthesis of taxanes where the fused bicyclic [5.3.1] system imposes a major challenge due to the presence of the eight-membered ring that is neither enthalpically nor entropically favorable. ${ }^{4}$ Furthermore the presence of a double bond at a carbon bridge-head provides additional strain to the structure. ${ }^{4,1 e}$ Inspired by the biosynthetic pathway of $\mathbf{1}$, in which the tandem cyclization of geranylgeranyl diphosphate, a polyenic precursor, generates the carbocyclic core, ${ }^{5}$ we designed a one step synthesis for the [5.3.1] bicyclic system of taxanes based on the cascade ringclosing dienyne metathesis (RCDEYM, Scheme 1). ${ }^{6}$ We believe that this approach fulfils the idea of rapid access to potential anticancer candidates. Previously we used this synthetic methodology to combine steroids and taxanes structures to make taxosteroids. ${ }^{7}$ Additionally, we observed that the cyclization of a dienyne built on a cyclohexyl scaffold with the

a. Centro Singular de Investigación en Química Biolóxica e Materiais Moleculares (CIQUS) and Departamento de Química Orgánica. Universidade de Santiago de Compostela.15782 Santiago de Compostela (Spain).E-mail: juanr.granja@usc.es t Dedicate to Professor Barry Trost on the occasion of his 75th birthday.

Electronic Supplementary Information (ESI) available: [details of any supplementary information available should be included here]. See DOI: $10.1039 / \times 0 \times x 00000 x$ same relative configuration in $\mathrm{C} 1, \mathrm{C} 2, \mathrm{C} 3$ and $\mathrm{C} 8$ than the natural product does not cyclize, but its diastereomer with the opposite configuration in $\mathrm{C} 1$ does (Scheme 1$).{ }^{7}$ In this scenario we envisioned that the replacement of the hydrogen atom at C1 by a hydroxyl group (Scheme 1, compound 2) would favor a preorganized conformation reactive towards the RCDEYM reaction. Our precedent with taxosteroids reactivity ${ }^{7}$ together with the reported work by the Prunet's group utilizing our synthetic approach to synthesize a taxane with the hydroxyl group at C1 supported this hypothesis. ${ }^{8}$ Inspired by the biosynthesis of terpene natural products, herein we report the rapid access to highly functionalized taxane analogues $(16,17,18$-trinortaxanes) by a cascade RCDEYM process reminiscent of the cyclase phase, ${ }^{9}$ to forge the [5.3.1] bicyclic system and further functionalization of the resulting taxadiene analogues just as it happens in the oxidase phase of natural products. ${ }^{10}$

\section{Results and discussion}

Taxane skeleton construction. As mentioned earlier, our synthetic approach took advantage of the tandem ring-closing

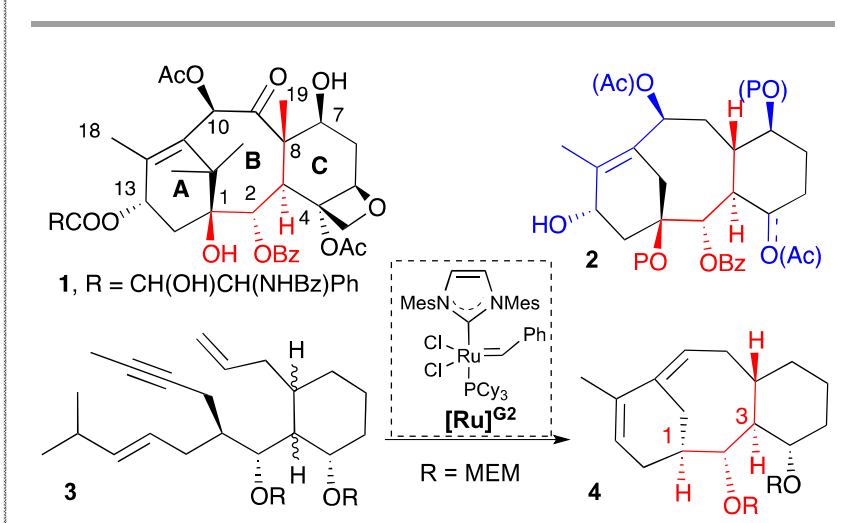

Scheme 1. Chemical structures of taxol (1) and highly oxidated taxoide 2, and previously reported RCDEYM for the rapid access to the [5.3.1] bicyclic system ( $\mathbf{A}$ and $\mathbf{B}$ ) of taxanes. 


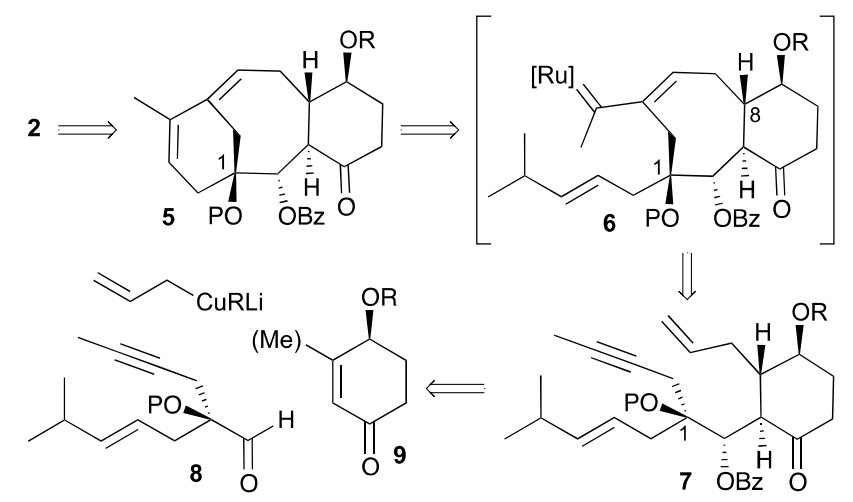

Scheme 2. Retrosynthetic analysis for the synthesis of taxane analogue 2 based on the cascade ring-closing metathesis of dienyne 7.

metathesis of acyclic dienynes (Scheme 2). ${ }^{11,12}$ Having in mind the biosynthesis of terpene-natural products, ${ }^{5}$ we envisioned a strategy (Scheme 2) where taxane analogues $\mathbf{2}$ could be easily accessed on a two-phase process: a tandem RCDEYM reaction of dienynes 7 (cyclase phase) ${ }^{9}$ and latter oxidation of the double bonds of $16,17,18$-trinortaxadienes 5 (oxidase phase) ${ }^{10}$. We reasoned that the cascade metathesis on dienyne 7 would start at the least substituted double bond to generate a metalcarbene intermediate that would subsequently react with the alkyne to give the metal alkylidene intermediate $\mathbf{6 .}^{13}$ Intermediate 6 would undergo a ring closing metathesis with the remaining double bond to give rise to the six-membered ring $A$ of taxadiene $\mathbf{5}$. Dienyne $\mathbf{7}$ was predicted to arise from the conjugate addition of allyl cuprate to cyclohexenone $\mathbf{9}$ followed by trapping of the resulting enolate with aldehyde $\mathbf{8}$ that carries the enyne moiety and the hydroxyl group on carbon $\mathrm{C} 1$. The use of 3-methylcyclohexenones could allow the incorporation of the methyl group at C8 (Me-19), although this goal was not addressed in the present work.

As outlined in the retrosynthetic scheme, we planned to set the configuration of $\mathrm{C} 1$ at an early stage to control the diastereoselective formation of the other chiral centres. To this end, we reasoned that the Sharpless epoxidation ${ }^{14}$ of allylic alcohol 12 (Scheme 3) would be the most reliable method to induce the required chirality. The synthesis of aldehyde $\mathbf{8}$ started with the alkylation of triethyl phosphonoacetate (10) with (E)-4-methyl-1-bromopent-2ene, ${ }^{15}$ Horner-Wadsworth-Emmons ${ }^{16}$ reaction of the resulting product with formaldehyde followed by reduction with DIBAL$\mathrm{H}$ of the ester afforded the allylic alcohol $\mathbf{1 2}$ in good yield. With compound $\mathbf{1 2}$ in hand, we were in position to install the C-O bond at $\mathrm{C} 1$ in an asymmetric fashion. Thus Sharpless epoxidation ${ }^{14}$ of allylic alcohol 12 using (-)-diisopropyl tartrate $[(-)-\text { DIPT }]^{16}$ as the chiral ligand produced epoxy-alcohol 13 with the natural product configuration (1S) in $93 \%$ yield and $90 \%$ enantiomeric excess. Addition of epoxide 13 in THF to a solution of 1-propynyllithium at $-78{ }^{\circ} \mathrm{C}$ afforded diol $14 \mathrm{a}$ in excellent yield. ${ }^{17}$ Finally, Swern oxidation ${ }^{18}$ followed by protection of the tertiary alcohol as a tert-butyldimethylsilyl ether provided aldehyde $\mathbf{8 a}$. Aiming to evaluate the effects of

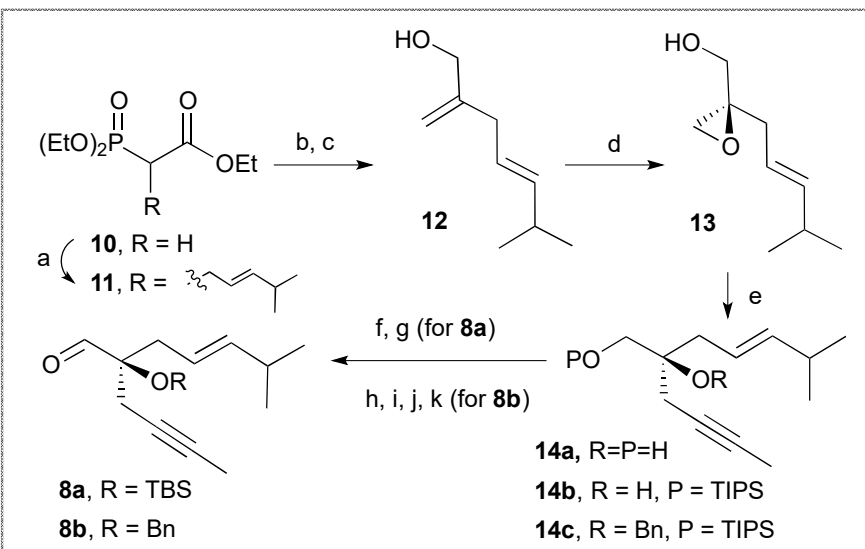

Scheme 3. Conditions: a) i. NaH, THF, ii. (E)-1-bromo-4methylpent-2-ene, 76\%; b) $\left(\mathrm{H}_{2} \mathrm{CO}\right)_{n}, \mathrm{~K}_{2} \mathrm{CO}_{3}, \mathrm{H}_{2} \mathrm{O}, 80{ }^{\circ} \mathrm{C}$; c) DIBAL-H, THF, $-78{ }^{\circ} \mathrm{C}$, 92\% (two steps); d) (-)-DIPT, $\mathrm{Ti}(\mathrm{PrO})_{4}, \mathrm{TBHP}, \mathrm{MS} 4 \AA \mathrm{CH}_{2} \mathrm{Cl}_{2}, 93 \%(90 \%$ ee); e) $1-$ bromoprop-1-ene, $n \mathrm{BuLi}, \mathrm{THF},-78{ }^{\circ} \mathrm{C}$ - r.t., 94\%; f) DMSO, $(\mathrm{COCl})_{2}, \mathrm{Et}_{3} \mathrm{~N}, \mathrm{CH}_{2} \mathrm{Cl}_{2},-78{ }^{\circ} \mathrm{C}, 73 \%$; g) TBSOTf, 2,6-lutidine, $\mathrm{CH}_{2} \mathrm{Cl}_{2}, 0{ }^{\circ} \mathrm{C}, 68 \%$; h) TIPSCl, $\mathrm{Et}_{3} \mathrm{~N}, \mathrm{DMAP}, \mathrm{CH}_{2} \mathrm{Cl}_{2}, 76 \%$; $)$ $\mathrm{NaH}, \mathrm{BnBr}$, TBAI, 15-crown-5, THF, 81\%; h) $\mathrm{HCl}$ (aq), $\mathrm{MeOH}$, $97 \%$; i) DMSO, $(\mathrm{COCl})_{2}, \mathrm{Et}_{3} \mathrm{~N}, \mathrm{CH}_{2} \mathrm{Cl}_{2},-78{ }^{\circ} \mathrm{C}, 83 \%$.

the steric congestion on the metathesis reaction, the benzylprotected aldehyde (8b) was also prepared. Direct benzylation of the unprotected aldehyde did not proceed as expected, for this reason we resorted to a four steps approach in which the primary alcohol was protected as a triisopropylsilyl ether (14b). Treatment of 14b with sodium hydride followed by benzyl bromide and tetrabutylammonium iodide provided the fully protected diol 14c. The use of other silyl groups (TBS or TMS) to protect the primary alcohol provided, under a variety of benzylation conditions, large amounts of the product derived from the silyl migration to the tertiary alcohol. ${ }^{17}$ Finally, the silyl group was removed under acidic conditions and the resulting alcohol was oxidized under Swern conditions to afford aldehyde $\mathbf{8 b}$ in $50 \%$ yield from diol $14 a$.

Once aldehydes $\mathbf{8 a}$ and $\mathbf{8 b}$ were synthesized, we set out to prepare the enynes precursors $\mathbf{1 7} \mathbf{a}, \mathbf{b}$ and $\mathbf{1 8 a , b}$ (Scheme 4). Conjugate addition of allyl cuprate to cyclohexenone followed by aldol reaction of the resulting enolate with aldehyde $\mathbf{8 a}$ provided dienynes 15a and 16a as an inseparable mixture of two trans-addition isomers in a 3:2 ratio and $75 \%$ yield. Similar results were obtained with aldehyde $\mathbf{8 b}$ to give $\mathbf{1 5 b}$ and $\mathbf{1 6 b}$ $(5: 3,79 \%)$. The trans configuration (C3-C8) was assumed, and later confirmed, based on the known anti-aldol selectivity. ${ }^{19}$ The resulting mixture was treated with benzoyl triflate or a mixture of benzoyl chloride and silver triflate in the presence of pyridine to give benzoates $17 \mathrm{a}, 18 \mathrm{a}$ and $17 \mathrm{~b}, \mathbf{1 8 b}$ in good yields. Similar to the alcohol precursors, these benzoates were inseparable by column chromatography. With the dienyne precursors in hand, we were able to test our hypothesis of whether the hydroxyl protected group at $\mathrm{C} 1$ is capable of favouring the RCDYEM reaction of the dienyne possessing the same stereochemistry as the natural product. To our delight, we observed that when the benzoates, as a mixture of the two diastereomers (17a and 18a), were treated with 6-10 mol\% of 


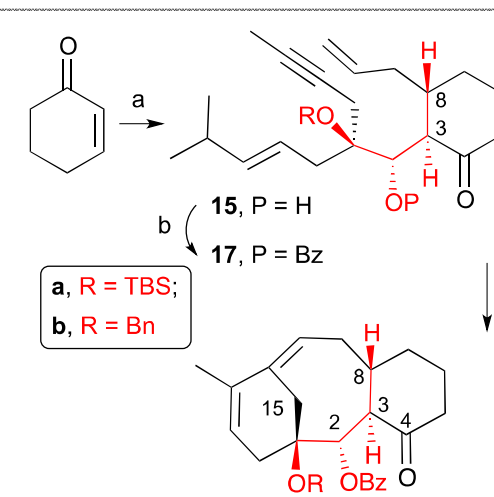

$19 a,(38 \%), 19 b,(35 \%)$

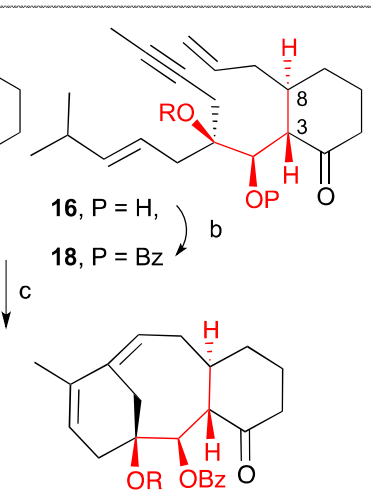

$20 \mathrm{a},(30 \%), 20 \mathrm{~b},(20 \%)$

Scheme 4. Conditions: a) i. AllylMgBr, CuBr.DMS, LiCl, THF, $-78{ }^{\circ} \mathrm{C}$, ii. $8 \mathrm{a} / \mathrm{b}, \mathrm{THF}, \mathrm{rt}, 75 \%$ for $15 \mathrm{a} / \mathbf{1 6 a}$ (3:2 ratio); $79 \%$ for 15b/16b (5:3 ratio); b) BzCl, TfOAg, py, THF, $60{ }^{\circ} \mathrm{C}, 77 \%$ for $17 \mathrm{a} / 18 \mathrm{a}$; $71 \%$ for $17 \mathrm{~b}$; $74 \%$ for $18 \mathrm{~b}$; c) $[\mathrm{Ru}]^{\mathrm{G} 2}, \mathrm{CH}_{2} \mathrm{Cl}_{2}$, reflux, $68 \%$ for $19 a / 20 a$; $55 \%$ for $19 b / 20 b$.

second generation Grubbs' catalyst $[\mathbf{R u}]^{\mathbf{G 2}}$ in refluxing dichloromethane provided two UV visible compounds that were identified as the tricyclic derivatives 19a and 20a (Scheme 4). Both compounds were easily separated by flash chromatography and obtained in 38\% (19a) and 30\% (20a) yields ( $68 \%$ overall yield). It is remarkable that dienynes 17 a and 18a easily gave the RCDEYM reaction products for two reasons: in previous examples the presence of the ketone in C4 resulted in starting material decomposition and moreover dienyne 17a cyclizes in very good yield even though the deoxystructure $\mathbf{3}$ (Scheme 1) with the same relative stereochemistry as $\mathbf{1}$ decomposed under the metathesis conditions. ${ }^{7}$ In addition, taxadiene 19a is the major product of the reaction. Similarly, treatment of the benzyl dienynes $17 \mathrm{~b}$ and $\mathbf{1 8 b}$ with the $[\mathbf{R u}]^{\mathrm{G2}}$ in dichloromethane also provided the corresponding tricylic products $19 \mathrm{~b}$ and $\mathbf{2 0 b}$ in similar yields. The relative stereochemistry of taxadienes was established by NOESY experiments and X-ray crystallography as shown in the appendix attached in the supporting information and illustrated in Fig $1 \mathrm{SI}$ and $2 \mathrm{SI}$.

In an attempt to improve the yields of the cyclization we treated dienynes 17a and 18a with 15 mol\% of the Grubbs catalyst $[\mathbf{R u}]^{\mathbf{G 2}}$ in benzene at $40{ }^{\circ} \mathrm{C}$ (Scheme 5). Under these conditions the cyclooctene derivatives $23 a$ and $24 a$ were obtained as a result of the diene-ring closing metathesis of the alkenes. Interestingly, treatment of this cyclooctene mixture (23a/24a) with $15 \mathrm{~mol} \%$ of the $[\mathbf{R u}]^{\mathbf{G 2}}$ catalyst in refluxing benzene for $1 \mathrm{~h}$ gave the corresponding taxadienes (19a and 20a) in $64 \%$ yield. This observation is interesting from the mechanistic standpoint, because this implies that in benzene these dienynes most likely undergo the ring-closing diene metathesis (RCM) faster than RCDEYM. Therefore the sequence of events it is in Scheme 5. Most probably, under these conditions a fast RCM provided the cyclooctene ring. At higher temperature, the ring opening metathesis (ROM) start to compete with the RCM to initially generates the metalcarbene complexes $\mathbf{2 5}$. The subsequent reaction of $\mathbf{2 5}$ with the alkyne moiety (enyne cyclization, RCEYM) forms the

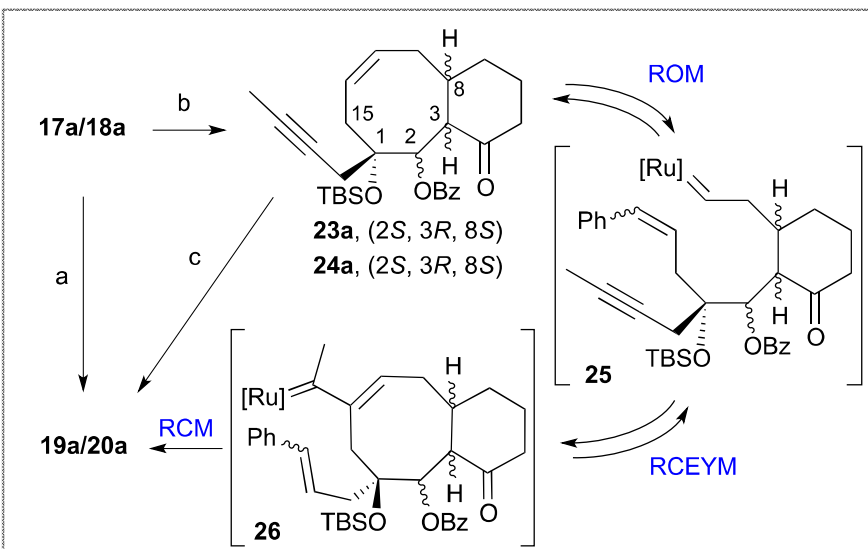

Scheme 5. Conditions: a) $[\mathrm{Ru}]^{\mathrm{G} 2}, \mathrm{C}_{6} \mathrm{H}_{6}, 40{ }^{\circ} \mathrm{C}, 74 \%$; b) [Ru] ${ }^{\mathrm{G2}}, \mathrm{C}_{6} \mathrm{H}_{6}$, reflux, 64\%; c) [Ru] ${ }^{\mathrm{G} 2}, \mathrm{CH}_{2} \mathrm{Cl}_{2}$, reflux, $68 \%$.

cyclooctene ring with concomitant formation of the metal alkylidene intermediates 26. Finally, ring-closing metathesis (RCM) of $\mathbf{2 6}$ with the last olefin moiety generates the sixmembered taxanes A-ring.

Synthesis of 4-tert-butylsilyloxy-taxadiene analogue 33a. One of the drawbacks of this approach is that the cuprate addition to the cyclohexenone forms two enantiomeric enolates which upon reaction with aldehydes $\mathbf{8} \mathbf{a}, \mathbf{b}$, provides two diastereomers, $\mathbf{1 5 a} \mathbf{a} \mathbf{b}$ and $\mathbf{1 6} \mathbf{a}, \mathbf{b}$, with the incoming aldehyde trans to the allyl group (Scheme 4). Additionally, only one of each pair $(\mathbf{1 5 a}, \mathbf{b})$ has the configuration of the natural product. Consequently a stereoselective cuprate addition was required to generate only one dienyne with relative and absolute stereochemistry matching that of taxol (1). To this end, we decided to install a bulky substituent (tertbutyldimethylsilyloxy) at $\mathrm{C} 4$ to direct the addition of the allyl group to the $\alpha, \beta$-unsaturated ketone $\mathbf{2 8}$ anti to the bulky group (Scheme 6). Moreover, this group at C4 corresponds with the hydroxyl group at $\mathrm{C} 7$ in the taxol skeleton. The pure enantiomer of the 4-(tert-butyldimethylsilyloxy)cyclohex-2enone (28) was prepared from (-)-quinic acid (27) according to procedures reported in the literature (see Scheme 1SI). ${ }^{21}$

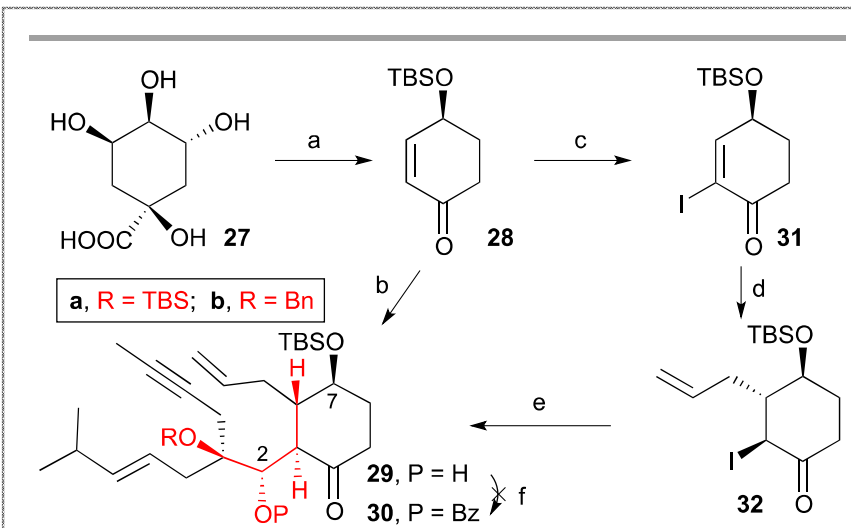

Scheme 6. Conditions: a) see Scheme $1 \mathrm{SI}$; b) i. AllylMgBr, CuBr.DMS, LiCl, THF, $-78{ }^{\circ} \mathrm{C}$; ii. 8a, THF, $-78{ }^{\circ} \mathrm{C}, 20 \%$; C) $\mathrm{I}_{2}, \mathrm{CCl}_{4}$, py, $0{ }^{\circ} \mathrm{C}, 78 \%$; d) AllylMgBr, CuBr.DMS, LiCl, THF, $-78{ }^{\circ} \mathrm{C}, 76 \%$; e) i. EtMgBr, THF, $0{ }^{\circ} \mathrm{C}$; ii. 8 b, THF, $0{ }^{\circ} \mathrm{C}, 50 \%$; f) $\mathrm{BzCl}, \mathrm{TfOAg}$, py, THF. $60^{\circ} \mathrm{C}$. 
When we subjected ketone $\mathbf{2 8}$ and aldehyde $\mathbf{8 a}$ to the previously optimized 1,4-addition-aldol reaction conditions, the addition product 29a was obtained as the sole diastereomer, although in $20 \%$ overall yield (40\% considering the recovered aldehyde). All attempts to optimize this transformation by changing the copper ( $\mathrm{CuCN}$, Cul, etc) or propenyl-metal sources ( $\mathrm{Li}$ or $\mathrm{Mg}$ ), reaction times and temperatures were unsuccessful. Alternatively, we trapped the enolate as trimethylsilyl or acetyl derivatives and used later to generate the reactive enolate under more appropriate conditions. Unfortunately, no reaction was observed after treatment of these enolate derivatives with a variety of organometalic reagents ( $n \mathrm{BuLi}, \mathrm{MeLi}, \mathrm{EtMgBr}$ ) or Lewis acids $\left(\mathrm{BF}_{3}, \mathrm{TiCl}_{4}\right.$ or $\left.\mathrm{SnCl}_{4}\right)$ in the presence of model aldehydes. To overcome this problem, ketone $\mathbf{2 8}$ was transformed into 2iodocyclohexenone $\mathbf{3 1}$ by treatment with iodine in carbon tetrachloride and pyridine. ${ }^{22}$ Compound $\mathbf{3 1}$ was then transformed into $\alpha$-iodoketone $\mathbf{3 2}$ by reaction with allylmagnesium bromide and copper bromide. Next, compound $\mathbf{3 2}$ was treated with ethylmagnesium bromide followed by addition of aldehyde $\mathbf{8} \mathbf{b}$ to afford hydroxyketone $29 \mathrm{~b}$ in $50 \%$ yield as a single diastereisomer. ${ }^{22}$ We tried to transform the alcohol at $\mathrm{C} 2$ into the benzoate, but previously described conditions failed to give the desired product. Despite previous observations that the metathesis of dienynes bearing the hydroxyl group on $\mathrm{C} 2$ and the ketone group on C4 provides complex reaction mixtures, ${ }^{6,7}$ we decided to subject the dienyne 29a to the RCDEYM conditions (Scheme 7). The metathesis-cyclization of this compound using $10 \mathrm{~mol} \%$ of the $[\mathbf{R u}]^{\mathrm{G2}}$ catalyst in refluxing dichloromethane provided the tricyclic derivative $33 a$ in $56 \%$ yield, together with the cyclooctene derivative $34 a(40 \%) .6,7,23$ It is worth noting that the cyclooctene intermediate 34 a can be transformed into the taxane derivative $\mathbf{3 3 a}$ by further treatment with the $[\mathbf{R u}]^{\mathbf{G 2}}$ catalyst. Taking into account this result, it is remarkable the ease of formation of the highly functionalized taxane skeleton by RCDEYM from acyclic dienynes anchored to a cyclohexane platform.

Taxane functionalization. Once the cyclization methodology was established (cyclase phase) our next objective was the incorporation of additional functional groups (oxidase-like phase) on the carbocyclic system in an efficient way. To demonstrate the potential of these taxadiene analogues as a valuable source of taxane-like derivatives we further functionalize the tricyclic core to install the hydroxyl group on

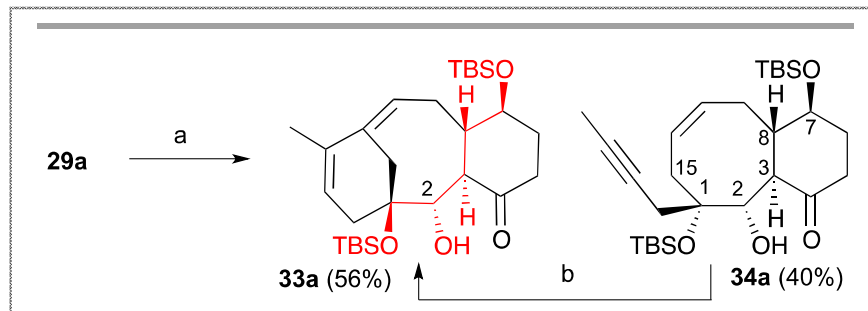

Scheme 7. Conditions: a) $[\mathrm{Ru}]^{\mathrm{G} 2}, \mathrm{CH}_{2} \mathrm{Cl}_{2}, 40{ }^{\circ} \mathrm{C}, 86 \%$; b) $[\mathrm{Ru}]^{\mathrm{G} 2}, \mathrm{C}_{6} \mathrm{H}_{6}, 90^{\circ} \mathrm{C}, 48 \%$.

C13 and acetoxy group on C10 (Scheme 8). To this end, we made use of the methodology previously developed in our group. ${ }^{7}$ Therefore treatment of compounds $19 a$ or 20 a (Scheme 8) with one equivalent of $m$-chloroperbenzoic acid (MCPBA) at $0{ }^{\circ} \mathrm{C}$ gave the oxiranes 21a and 36a in 65\% and $76 \%$ yields, respectively. In both cases, the oxygen addition took place, as expected, at the most strained and therefore more reactive $\mathrm{C} 10-\mathrm{C} 11$ double bond and through the least hindered $e$ ?] ]-face. The X-ray diffraction of crystals of this compound, as mentioned before, allowed us to confirm the proposed structure (Fig 2Sla). Hydroboration-oxidation of natural configuration precursor 21a gave complex mixtures in which the expected alcohol 35a was not observed. All attempts to carry out this transformation under milder conditions were unsuccessful. On the other hand, the hydroboration-oxidation only took place on epoxide 36a to afford 22a in very good yield. The addition of the borane took place from the $e$ ? ?]-face. In addition to the reaction of the double bound, under these conditions the ketone group was also reduced, with the diastereoselectivity dictated by the approach of borane from the least hindered $\beta$-face. The relative stereochemistry was assigned by NOESY experiments and as previously described by X-ray crystallography (Fig 2SIb). The structure calculated from the X-ray data showed the expected taxane-like system with all of the oxygenated substituents oriented to the same face ( $\beta$-face). As the resulting alcohol at $\mathrm{C} 13$ has the opposite configuration of the natural product, we corrected the stereochemistry by an oxidation-reduction procedure. The oxidation of 22a with PDC was followed by treatment of the resulting crude mixture with alumina and acetic anhydride in the presence of DMAP to give diacetylketone $37 \mathrm{a}$ in $75 \%$ yield. Interestingly, only the hydroxyl group at C13 was oxidized under these conditions while the hydroxyl group in C4 remained unaffected. Finally, Luche's reduction of the unsaturated ketone provided allylic alcohol $\mathbf{3 8 a}$ in almost quantitative yield. The resulting

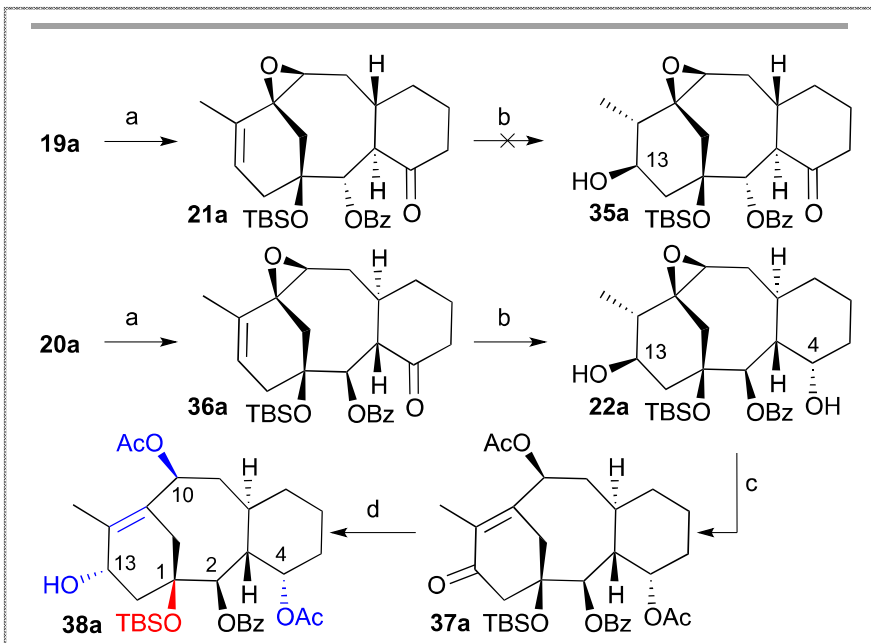

Scheme 8. Conditions: a) MCPBA, $\mathrm{CH}_{2} \mathrm{Cl}_{2}, 0{ }^{\circ} \mathrm{C}, 62 \%$ for 21a, $76 \%$ for 36a; b) i. $\mathrm{BH}_{3}$. THF, $\mathrm{CH}_{2} \mathrm{Cl}_{2}, 0{ }^{\circ} \mathrm{C}$, ii. $\mathrm{NaOH}, \mathrm{H}_{2} \mathrm{O}_{2}, 76 \%$ for 22a; c) i. PDC, $\mathrm{CH}_{2} \mathrm{Cl}_{2}$, ii. $\mathrm{Al}_{2} \mathrm{O}_{3}, \mathrm{CH}_{2} \mathrm{Cl}_{2}$, iii. $\mathrm{Ac}_{2} \mathrm{O}$, DMAP, $74 \%$; d) $\mathrm{NaBH}_{4}, \mathrm{CeCl}_{3} .7 \mathrm{H}_{2} \mathrm{O}, \mathrm{MeOH}, 0{ }^{\circ} \mathrm{C}, 96 \%$.

compound has the hydroxyl group in the endo position, which 
is the same as the natural product. Additionally, the obtained taxane precursor bears some of the key features of the natural product, such as the benzoate at $\mathrm{C} 2$, the protected hydroxyl group at $\mathrm{C} 1$, the acetates at $\mathrm{C} 4$ at $\mathrm{C} 10$ and the free hydroxyl group ready to incorporate the amino acid side chain. ${ }^{24}$

To resolve the observed problem in the reactivity of the isomer with the natural configuration, a different alternative was approached. For this purpose, we studied the incorporation of the 2-en-1,4-diol system presented on taxol through the previously developed ring opening of diepoxides through a titanium induced radical methodology. ${ }^{25}$ For this purpose the diene 19a was treated with MCPBA at $0{ }^{\circ} \mathrm{C}$. Unfortunately a mixture of diepoxides $37 a$ and 38 a in a $1: 3$ ratio was obtained in $64 \%$ overall yield (Scheme 9). Both epoxides are differentiated in the relative orientation of epoxide at $\mathrm{C} 12-\mathrm{C} 13$. The major isomer was the one with the $\beta$ face configuration that was, in previous studies, the only isomer that underwent the double oxirane opening. This isomer is the precursor of a synthetic intermediate with opposite configuration at $\mathrm{C} 13 .{ }^{25}$ Mechanistically, the process was explained based on a titanium induced sequential epoxide opening of dioxirane moiety. ${ }^{26}$ The observed lack of reactivity of the trans-diepoxide was justified at that time in terms of the steric hinderance provided by the tricyclic skeleton. ${ }^{25}$ The resulting diepoxides were subjected with the in situ generated titanocene (III) complex. ${ }^{26}$ Interestingly both of them underwent the double opening to provide diols 39a and 40a in 58 and $52 \%$ yield, respectively. Therefore, we have accessed to a highly advanced precursor taxane analogues with the configuration of the natural product although, at this moment, as the minor product. The main product in this strategy has the opposite configuration at $\mathrm{C} 13$ but the previously developed sequence based on the oxidation/reduction should allow inverting the configuration of this stereogenic center.

\section{Conclusions}

In summary, we were able to install the stereogenic center at C1 with the same configuration of taxol (1) using the asymmetric Sharpless epoxidation. We showed that the protected hydroxyl group at C1 indeed favors the cascade ring-

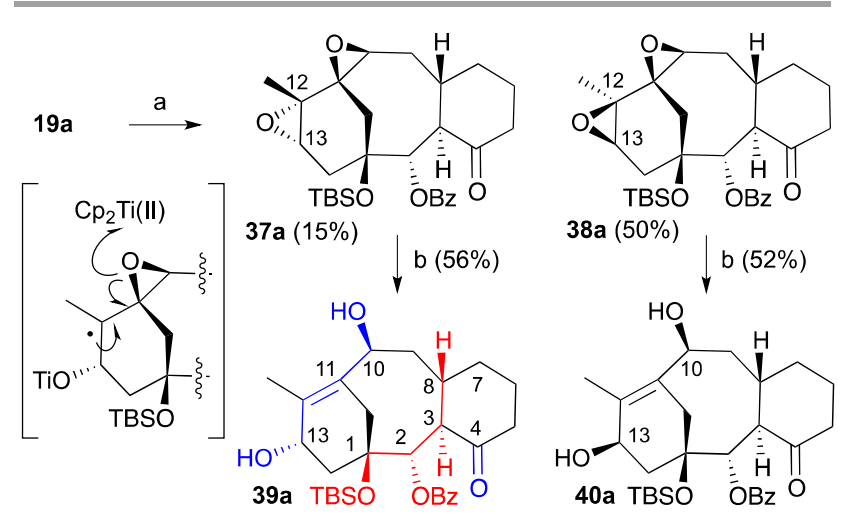

Scheme 9 Conditions: a) MCPBA, $\mathrm{CH}_{2} \mathrm{Cl}_{2}, 64 \%$; b) $\left[\mathrm{Cp}_{2} \mathrm{TiCl}_{2}\right]$, $\mathrm{Zn}, \mathrm{THF}, 0^{\circ} \mathrm{C}$. closing dienyne metathesis (RCDEYM) of dienynes 17a,b featuring a ketone at $\mathrm{C} 4$ and with the same stereochemistry at $\mathrm{C} 1, \mathrm{C} 2, \mathrm{C} 3$ and $\mathrm{C} 8$ of the natural product that previously have proven to be unreactive and without the need of additional tethering that pre-organize the reactive unsaturations. Therefore, we were able to prepare the taxadiene analogues 19a,b, 20a,b and 33a furnished with the oxygenated functional groups at $\mathrm{C} 1$ and $\mathrm{C} 2$ along with the ketone at $\mathrm{C} 4$, the two double bonds $\mathrm{C} 10-\mathrm{C} 11$ and $\mathrm{C} 12-\mathrm{C} 13$ that allow for further functionalization. It was observed that the cascade RCDEYM of dienyne 29a, carrying the seemingly labile groups ketone at $\mathrm{C} 4$ and unprotected alcohol at $\mathrm{C} 2$, takes place at unprecedented high yield. We demonstrated the potential of these taxadiene analogues as a source of various derivatives by further functionalization, oxidase-like phase, of 19a to prepare the 16,17,18-nortaxane 39a furnished with the hydroxyl groups in $\mathrm{C} 10, \mathrm{C} 13$, the double bond $\mathrm{C} 11-\mathrm{C} 12$ and a carbonyl group at C4.

\section{Acknowledgements}

This work was supported by the Spanish Ministry of Economy and Competitivity (Mineco) and the ERDF (CTQ2010-15725, CTQ2013-43264-R and CTQ2014-51912-REDC), and by the Xunta de Galicia and the ERDF (GPC2013-039, EM2012/117 and EM2014/011). N. S. thanks Mineco for his FPU contract and S. P.-E. to the CONACYT for his fellowship (No. 162219). We also thank ORFEO-CINCA network.

\section{Notes and references}

1 a) M. Suffness, TAXOL ${ }^{\circ}$ : Science and Applications (CRC Press, 1995); b) H. Itokawa, K.-H.Lee, Taxus: The Genus Taxus (Taylor \& Francis, 2003); c) V. A. Weger, J. H. Beijnen, J. H. M. Schellens, Anti-Cancer Drugs 2014, 25, 488; d) J. A. Yared, K. H. R. Tkaczuk, Drug Des. Dev. Ther. 2012, 6, 371; e) Y.-F. Wang, Q.-W. Shi, M. Dong, H. Kiyota, Y.-C. Gu, B. Cong, Chem. Rev. 2011, 111, 7652.

2 a) J. N. Denis, A. E. Greene, D. Guenard, F. GueritteVoegelein, L. Mangatal, P. Potier, J. Am. Chem. Soc. 1988, 110, 5917; b) I. Ojima, I. Habus, Zhao, M., Zucco, M., Park, Y. H., Sun, C. M., Brigaud, T., Tetrahedron, 1992, 48, 6985.

3 a) R. Krisna, L. D. Mayer, Eur. J. Phar. Sci. 2000, 11, 265; b) G. Arpino, S. De Placido, C. De Angelis, Anti-Cancer Drugs 2015, 26, 117; c) Z. Liu, F. Zhang, G. Y. Koh, X. Dong, J. Hollingsworth, J. Zhang, P. S. Russo, P. Yang, R. W. Stout, Anti-Cancer Drugs 2015, 26, 167; d) S. Koudelka, J. Turánek, J. Control. Release 2014, 163, 322; e) P. Ma, R. J. Mumper, J. Nanomed. Nanotechnol. 2013, 4, 1; f) P. Zhao, D. Astruc, ChemMedChem 2012, 7, 952.

4 a) K. C. Nicolaou, Z. Yang, J. J. Liu, H. Ueno, P. G. Nantermet, R. K. Guy, C. F. Claiborne, J. Renaud, E. A. Couladouros, K. Paulvannan, E. J. Sorensen, Nature, 1994, 367, 630; b) R. A. Holton, H. B. Kim, C. Somoza, F. Liang, R. J. Biediger, P. D. Boatman, M. Shindo, C. C. Smith, S. Kim, J. Am. 国hem. Soc. 1994, 116, 1599.

5 a) S. Howat, B. Park, I. S. Oh, Y.-W. Jin, E.-K. Lee, G. J. Loake, New Biotechnology 2014, 31, 242; b) R. Croteau, R. E. B. Ketchum, R. M. Long, R. Kaspera, M. R. Wildung, Phytochem. Rev. 2006, 5, 75; c) H. Li, T. Horiguchi, R. Croteau, R. M. Williams, Tetrahedron 2008, 64, 6561 
6 a) R. García-Fandiño, E. M. Codesido, E. Sobrazo-Sánchez, L. Castedo, J. R. Granja, Org. Lett. 2004, 6, 193; b) M. J. Aldegunde, R. García-Fandiño, L. Castedo, J. R. Granja, Chem. Eur. J. 2007, 13, 5135.

7 M. J. Aldegunde, L. Castedo, J. R. Granja, Org. Lett. 2008, 10, 3789.

8 a) A. Letort, R. Aouzal, C. Ma, D.-L. Long, J. Prunet, Org. Lett. 2014, 16, 3300; b) C. Ma, A. Letort, R. Aouzal, A. Wilkes, G. Maiti, L. J. Farrugia, L. Ricard, J. Prunet, Chem. Eur. J. 2016, 22, 6891 .

9 a) P. D. Goldring, G. Pattenden, S. L. Rimmington, Tetrahedron 2009, 65, 6670; b) J. Petrignet, A. Boudhar, G. Blond, J. Suffert, Angew. Chem. Int. Ed. 2011, 50, 3285; c) A. Mendoza, Y. Ishibara, P. S. Baran, Nat. Chem. 2012, 4, 21.

10 a) N. C. Wilde, M. Isomura, A. Mendoza, P. S. Baran, J. Am Chem. Soc. 2014, 136, 4909; b) Y. Ishihara, A. Mendoza, P. S. Baran, Tetrahedron 2013, 69, 5685; c) K. Chen, P. S. Baran, Nature 2009, 459, 824; d) C. Yuan, Y. Jin, N. C. Wilde, P. S. Baran, Angew. Chem. Int. Ed. 2016, 55, 8420.

11 a) A. Michaut, J. Rodriguez, Angew. Chem. Int. Ed. 2006, 45, 5740; b) M. E. Maier, Angew. Chem. Int. Ed. 2000, 39, 2073.

12 a) T. J. Katz, T. M. Sivavec, J. Am. Chem. Soc. 1985, 107, 737; b) S.-H. Kim, W. J. Zuercher, N. B. Bowden, R. H. Grubbs, J. Org. Chem. 1996, 61, 1073; c) W. J. Zuercher, M. Scholl, R. H. Grubbs, J. Org. Chem. 1998, 63, 4291; d) F.-D. Boyer, I. Hanna, L. Ricard, Org. Lett. 2004, 6, 1817; f) I. Dragutan, V. Dragutan, A. Demonceau, L. Delaude, Concepts Curr. Org. Chem. 2013, 17, 2678.

13 a) R. García-Fandiño, L. Castedo, J. R. Granja, D. J. Cárdenas, Dalton Trans. 2007, 2925; b) F. Núñez-Zarur, X. SolansMonfort, L. Rodríguez-Santiago, M. Sodupe, ACS Catal. 2013, 3, 206; c) F. Núñez-Zarur, X. Solans-Monfort, L. RodríguezSantiago, R. Pleixats, M. Sodupe, Chem. Eur. J. 2011, 17, 7506; d) O. S. Lee, K. H. Kim, J. Kim, K. Kwon, T. Ok, H. Ihee, H.-Y. Lee, J.-H. Sohn, J. Org. Chem. 2013, 78, 8242.

14 a) Katsuki, T.; Martin, V. Asymmetric epoxidation of allylic alcohols: The Katsuki-Sharpless epoxidation reactions en: Organic Reactions Vol. 48., Ojima, J. Ed.: Wiley-VCH (Wheinheim) 1996. b) Schinzer, D. Asymmetric synthesis. The Sharpless epoxidation en: Organic Synthesis Highlights II Waldmann, H. Ed.: Wiley-VCH (Wheinheim) 1995.

15 A. van derKlei, R. de Jong, J. Lugtenburg, A. Tielens, Eur. J. Org. Chem. 2002, 17, 3015.

16 J. M. Schomaker, B. Borham, Org. Biomol. Chem. 2004, 2, 621.

17 D. Toussaint, J. Suffert, Org. Synth. 1999, 76, 214.

18 D. Evans, S. W. Kaldor, T. K. Jones, J. Clardy, T. J. Stout, J. Am. Chem. Soc. 1990, 112, 7001.

19 B. Schetter, R. Mharwald Angew. Chem., Int. Ed. 2006, 45, 7506.

20 a) H. D. Flack Acta Cryst. 1983, A39, 876; b) H. D. Flack, G. Bernardinelli J. Appl. Cryst. 2000, 33, 1143.

21 a) B. M. Trost, A. G. Romero, J. Org. Chem. 1986, 51, 2332; b) Z. X. Wang, S. M. Miller, O. P. Anderson, J. Org. Chem. 1999, 64, 6443; c) J. E. Audia, R. Boisvert, A. D. Patten, A. Villalobos, S. J. Danishefsky, J. Org. Chem. 1989, 54, 3738.

22 D. A. William, Y. Kobayashi J. Org. Chem. 2002, 67, 8771.

23 a) L. Hyldtoft, R. Madsen, J. Am. Chem. Soc. 2000, 122, 8444; b) B. M. Kariuki, W. M. Owton, J. M. Percy, S. Pintat, C. A Smith, N. S. Spencer, A. C. Thomas, M. Watson Chem. Commun. 2002, 228.

24 T. Ganesh, C. Yang, A. Norris, T. Glass, S. Bane, R. Ravindra, A. Banerjee, B. Metaferia, S. L. Thomas, P. Giannakakou, A. A Alcaraz, A. S. Lakdawala, J. P. Snyder, D. G. I. Kingston J. Med. Chem. 2007, 50, 713.

25 M. J. Aldegunde, L. Castedo, J. R. Granja, Chem. Eur. J. 2009, 15,4785 .
26 K. Daasbjerg, H. Svith, S. Grimme, M. Gerenkamp, C. MückLichtenfeld, A. Gansäuer, A. Barchuk, F. Keller, Angew. Chem. Int. Ed. 2006, 45, 2041; A. Gansäuer, A. Barchuk, F. Keller, M. Schmitt, S. Grimme, M. Gerenkamp, C. MückLichtenfeld, K. Daasbjerg, H. Svith, J. Am. Chem. Soc. 2007, 129, 1359; A. Gansäuer, C.-A. Fan, F. Keller, J. Keil, J. Am. Chem. Soc. 2007, 129, 3484. 